\title{
Detection of Biological Activity of Curcuma longa Methanol Extract and Its Antibacterial effect on Staphylococcus aureus.
}

\author{
Covenant Ogbonna ${ }^{1 *}$, Erkay Özgör ${ }^{2,3}$
}

\begin{abstract}
Plants are known to possess enormous profound benefits, which if well incorporated in daily living have the potential to influence our health in ways unexpected. Significant progress has been made concerning the anti-oxidative and anti-cancerous effect of bioactive components in food products, worthy of note in the curcuminoids derived from turmeric (Curcuma longa) rhizomes. Therefore, to this end, this research aims to describe succinctly the phytocomponents, antioxidant activity and antimicrobial activity of turmeric methanol extract. The zones of inhibition were measured after plating on a Mueller Hinton agar plate and compared to the standards penicillin $\mathrm{G}$ and chloramphenicol. Chloramphenicol used as a positive control was found to be most effective on Staphylococcus aureus while Curcuma longa methanol extract and penicillin G were found to have the same microbial inhibition due to the negative control. Compared to the IC50 values of Ascorbic acid which was $5 \mathrm{mg} / \mathrm{ml}$, Curcuma longa methanol extract had a lower IC50 value is $3.2 \mathrm{mg} / \mathrm{ml}$ which according to previous literature is a good one given that lower IC50 values indicate great antioxidant activity. It was gathered by the observation that the qualitative extraction of Curcuma longa using methanol shows the presence of varying chemical components such as AR-tumerone, arachinsaeure, alpha-tumerone amongst others. Research data suggest that ar-turmerone has the potential to promote the positive and negative proliferation of tumor cell lines. As a result, Curcuma longa has high potential to be developed into an antibiotic against Methicillin-resistant Staphylococcus aureus and other clinically important bacterial strains in future.
\end{abstract}

Keywords: Curcuma longa, antimicrobial activity, antioxidant activity, Staphylococcus aureus

${ }^{1}$ Cyprus International University, Department of Bioengineering, 99258, Nicosia, Mersin 10, TURKEY

${ }^{2}$ Cyprus International University, Department of Molecular Biology and Genetics, 99258, Nicosia, Mersin 10, TURKEY

${ }^{3}$ Cyprus Bee and Bee Products Research Centre,

Cyprus International University, 99258, Nicosia,

Mersin 10, TURKEY

${ }^{*}$ Corresponding author: e-mail:

covenantsdg2017@gmail.com

phone: +90 3926711111, fax: +90 3926711122

DOI: $10.2478 /$ ebtj-2021-0009

(C) 2021 Authors. This work was licensed under the Creative Commons Attribution-NonCommercialNoDerivs 4.0 License.

\section{Introduction}

Plants are known to possess enormous profound benefits, which if well incorporated in daily living have the potential to influence our health in ways unexpected. However, it is worthy of note that certain plant components are known to be comprised of esters, inorganic and organic components, in some cases hydrocarbons which play a role in increasing the vitality of the human system. Certain plants are known to possess increased antioxidant activity, antimicrobial activity, carminative effects, repair of dead cells, ability to boost cardiovascular stability.

Fiber is of great importance in metabolic activity of our digestive system, and our overall health by improving blood cholesterol, abating lung and colon cancer and the prevention of diseases like diabetes. Over time, fibers have been obtained from husks of corn, stalks of cotton, straws of wheat, barley and rice and peels of plantain or banana, citrus husks amongst others (1). Curcuma longa is a resourceful member of the Zingiberaceae family. Turmeric identified botanically as $C$. longa is often cultivated for the importance of its rhizomes, however, the plant produces a substantial amount of leaves and stem from which oil and other extractives are derived (2).

Turmeric is mostly consumed as a yellow powdered spice with an aesthetic flavor and 
medicinal prowess capable of preserving the freshness of the product prepared. In traditional medicinal practices, turmeric has been used in its various forms to combat one or more health conditions ranging from stomach aches, to use as a blood purifier to the treatment of skill anomaly. However, the predominant application of turmeric is observed and described as antimicrobial, anticancer, antitumor, wound healing, venom antidotes and also hepatic-protective (3).

Only recently analyzed anti-oxidative potential in food products become a thing of worldwide acceptance and interest. Significant progress has been made in relation to anti-oxidative and anti-cancerous effect of bioactive components in food products, worthy of note in the curcuminoids derived from turmeric rhizomes (4).

Worthy of note is the attribute of turmeric which makes it a dye for artistic representation, for textile products, for use in drugs against cancer, dermatitis, AIDS. With regards to the significance which bioactive constituents in herba naturale wield, there is an ever-growing discontent with better extraction methods and detailed means of phenotyping these components. To this effect, various spectrometric methods have sufficed including the HPLC-MS, GC-MS amongst others (5).

The composition and volatility of Curcuma longa extracts is the basis of the characteristic smell moreover, fixed phenolic compounds like curcumin are a requisite for their intense yellow color (6). A wide input of clinical studies on standardized curcumin has described beneficial pharmacological effects and plausible functional food ingredient or therapeutic agent (7).

The rhizome is about $2-10 \mathrm{~cm}$ in length, cylindrical, ovoid, branched and deep in orange color. A recent report on methanol extract of a species of turmeric shown a significantly strong antifungal activity besides its known anti-bacterial activity (8). In general, essential oils from Curcuma spp. are complex mixtures of sesquiterpenes, monoterpenes and aromatic compounds, which have been shown strong antioxidative, anti-inflammatory and anti-bacterial activities. Germacrone can also inhibit the proliferation of MCF-7 by inducing cell cycle arrest and triggering apoptosis (9).

Organic extracts of turmeric prevent curtailed DNA sabotage. The anti-inflammatory and antioxidant effects of this natural rhizome according to several studies appear to inhibit cancer induced by the cell cycle. Besides tumerone, curcumin is also an active agent in turmeric for in treating several types of cancer examples include breast cancer and lung cancer, by promoting cancer cell death, through curtailed immune responses in form of inflammation, and slowing down tumor growth. It also contains (Superoxide dismutase 1 (SOD1)), which has proven potential to prevent cancerous cell development in the prostate as well as to inhibit secondary melanoma, the tumor of the brain, amongst others (10). One of the bottlenecks in the application of turmeric as a therapeutic agent is that it can be easily metabolized or broken down within the body which could result in double bonds in the reduction of di-bonds in heptadienedione chain. A secondary outcome of this will be the production of the active metabolite (11).
Many researchers have pointed out the ability of turmeric to exhibit anticancer activity with a dual-phase pattern which affects the proteasome, such that at decreased doses of application there will be higher inhibitory effects. As is rightly known, inhibition of proteasome has the potential to induce cell death however, its stimulation could also provoke cell stimulation for survival even though this is largely dependent on the application dosage. Cumulatively, various application doses of the turmeric extract could result in alternative cell death options, this is to say that low application doses might affect the pattern of apoptosis and oxidative stress, while the higher application doses might lead to reduced availability of ROS species (12).

Therefore, to this end, this research aims to describe succinctly the phytochemical components, antioxidant activity and antimicrobial activity of turmeric (Curcuma longa) methanol extract.

\section{Materials and Methods}

\subsection{Preparation of Curcuma Longa methanol extract}

All plant materials (dried powdered turmeric rhizomes) which are grown on a farm in Nicosia, Cyprus (Lat-Long: 35.050179, 33.716818) were collected, cleaned, freeze-dried at $-80^{\circ} \mathrm{C}$ and ground into a fine powder by grinder. The method adapted for this extraction was as described by Kutti Gounder and Lingamallu (3). Turmeric (Curcuma longa) rhizome powder extract was prepared by mixing $50 \mathrm{~g}$ of powdered leaf in $400 \mathrm{ml}$ HPLC grade methanol in an Erlenmeyer flask and stirred for 48 hours on an overhead shaker at room temperature kept in boiling water bath for $10 \mathrm{~min}$. The extract was filtered through Whattman filter paper No.5 and stored in the refrigerator. The extract was recovered by the use of a rotary evaporator at 40 $\mathrm{rpm}$ at a temperature of $50^{\circ} \mathrm{C}$ for an hour. The dry mass of extracts was stored for further use.

\subsection{Gas chromatography-mass spectrometry}

The different solvent extracts were analyzed by gas chromatography-mass spectrometry (GC-MS) according to certain conditions (13). The GC or GC-MS conditions were optimized based on the property of the various solvent extract. HP-5 fused silica capillary column $(30 \mathrm{~m} \times 0.25 \mathrm{~mm}$, film thickness $0.25 \mu \mathrm{m}$ ). Helium (purity 99.99\%) was used as the carrier gas, with a flow rate of $0.9 \mathrm{~mL} / \mathrm{min}$. The column oven temperature was programmed from $50^{\circ} \mathrm{C}$ (hold $1 \mathrm{~min}$ ) to $240^{\circ} \mathrm{C}$ (hold 10 $\min$ ) at a $5^{\circ} \mathrm{C} / \mathrm{min}$ rate. C. longa methanol extracts injected in an Agilent 7890A GC system coupled with an MS (Agilent technologies) by author injection at the environmental laboratory, Cyprus International University. The operating conditions of the GC-MS set for the analysis were as follows: oven temperature was set at $50^{\circ} \mathrm{C}$ for $2 \mathrm{~min}$ then $100^{\circ} \mathrm{C}$ at $10^{\circ} \mathrm{C} / \mathrm{min}$ and steadily increased to $200^{\circ} \mathrm{C}$ and held at a constant temperature for $10 \mathrm{~min}$. The sample injection volume was $2 \mu \mathrm{L}$ and the carrier gas was helium at $1 \mathrm{~mL} / \mathrm{min}$. The ionization of the sample components was carried out $70 \mathrm{eV}$. The total time of the GC analysis was $24.50 \mathrm{~min}$ for $C$. longa methanol extracts. 


\subsection{DPPH Free radical-scavenging ability}

The DPPH radical-scavenging activity was determined using the method shown by Tavares et al. (6). $100 \mu \mathrm{M}$ DPPH was dissolved in pure methanol (96\%). The stock solution was prepared fresh. The DPPH solution $3 \mathrm{ml}$ was added to $1 \mathrm{ml}$ of $C$. longa methanol extracts across the quintuplet concentrations. The mixture was shaken and allowed to stand at $37^{\circ} \mathrm{C}$ for 10 min in the dark. The decrease in absorbance of the resulting solution was calculated for $10 \mathrm{~min}$ at $517 \mathrm{~nm}$ with ELISA Reader. The results were corrected for dilution and expressed in $\mathrm{mg} /$ $\mathrm{ml}$. All determinations were performed in duplicate.

\subsection{Antimicrobial assessment by disc diffusion plate method}

Curcuma longa methanol extracts for antimicrobial tests were centrifuged and filtered with sterile $0.45 \mu \mathrm{m}$ microfilter. Staphylococcus aureus (ATCC 6538 P), was serially diluted with nutrient broth and incubated for 24 hours at the optimum temperature of $37^{\circ} \mathrm{C}$. Briefly, Mueller Hinton agar plates were prepared by weighing out grams of the powdered media and dissolving in distilled water then autoclaved at $121^{\circ} \mathrm{C}$ at $15 \mathrm{psi}$ for $15 \mathrm{mins}$. After which the sterile media is aseptically poured into $60 \mathrm{~mm}$ petri dishes and allowed to dry before the experiments. Standard antibiotic concentrations chloramphenicol (1 $\mathrm{mg} / \mathrm{ml}$ ) were used as a positive control for the sake of this while for the negative control DMSO (0.9\%) solution prepared. Also, McFarland standard as a basis for the preparation of the bacterial suspension sequel to which $200 \mu$ of the suspension was added to the agar plate and spread evenly onto the agar surface. $6 \mathrm{~mm}$ discs were loaded with 30ul of C. longa methanol extracts and incubation was done for $24 \mathrm{hrs}$ at $37^{\circ} \mathrm{C}$. The areas or diameter of inhibition was observed and measured in the units of a millimeter $(\mathrm{mm})$. Every process was performed aseptically in duplicates. After the disc diffusion method, SPSS 16 software was used for statistical evaluation of zone diameters (in millimeters) measurement data. The effectiveness of $C$. longa was evaluated with the Duncan test for $S$. aureus.

\section{Results}

\subsection{Gas chromatography-mass spectrometry}

Table 1 shows the occurrence of the various bioactive compound as observed by different organic solvents. Some compounds were in increased occurrence depending on the solvent of choice.

\subsection{DPPH Free radical-scavenging ability}

The DPPH radical-scavenging activity evaluated to detect the antioxidant capacity of $C$. longa. Antioxidants over time have found relevance in many ways ranging from additives to preservatives to combat oxidative degradation of food. There are a variety of synthetic chemicals which possess radical scavenging ability, however alongside their positive effect lies their negative effect which poses a bottleneck to their advancement of application (5). The human race more than ever has an interest in greener and sustainable sources for the production of goods and services. The IC50 values of $C$. longa and standard are shown in Table 2 and the \% DPPH radical-scavenging according to the volume of $C$. longa is shown in Figure 1.

\subsection{Antimicrobial assessment by microdilution and disc diffusion method}

The broth microdilution plates were prepared and read with a microplate reader at a wavelength of $630 \mathrm{~nm}$, it was observed in comparison with the 0.5 standard bacterial McFarland solution which has a standard turbidity measurement. Observably as the concentration of the treatment reduced, turbidity reduced likewise across test organisms. The MIC for this research was determined as the lowest concentration that didn't have color change after inoculating the microorganism with a similar concentration as the McFarland standard. In Table 3, the minimum inhibitory concentrations (MIC) and Minimum bactericidal concentration for $S$. aureus were $12.5 \mathrm{mg} / \mathrm{ml}$ and $25 \mathrm{mg} / \mathrm{ml} \mathrm{re}$ spectively. Figure 2 shows the MIC and MBC of $C$. longa on $S$. aureus.

The comparison of zone diameters at the disc diffusion test showed that there is a significant difference between the Curcuma longa extract compared with antibiotics and negative control ( $\mathrm{p}<0.05)$. Chloramphenicol used as a positive control was found to be most effective on S. aureus. However, C. longa methanol extract and penicillin $G$ were found to have the same microbial inhibition due to the negative control by the Duncan test (Table 4).

\section{Discussion}

Many researchers who tested different plant extracts against bacteria and yeast observed their antimicrobial activities. Plant extracts contain lots of active chemical compounds which show potential antimicrobial activities. Plants whose have especially rhizomes contain lots of active substances in terms of antimicrobial and anticancer activities. Curcuma longa is one of these plants who has economic and industrially-important substances inside.

It was gathered by the observation that the qualitative extraction of $C$. longa using methanol shows the presence of varying chemical components such as AR-tumerone, arachinsaeure, alpha-tumerone amongst others (Table 1). Arachnsaeure finds its relevance in ointment formulation of face, body, and hand skincare products, moisturizers, anti-aging formulations, and other skincare products. Research data suggest that ar-turmerone has the potential to promote the positive and negative proliferation of tumor cell lines. However, ar-turmerone inhibited the proliferation of certain cancer cell lines, it enhanced the proliferation of a special type cell; peripheral blood mononuclear cells (14). Alternative research was conducted, showed that when the alpha tumerones and aromatic tumerones were used in the same amounts, a significantly higher amount of curcumin was detected inside the cells. The results also describe that changes in transport of curcumin are largely depended on the tumerones (15). Results showed that alpha tumerones mainly contributed to the 
Table 1. Showing the GC-MS profiling of Curcuma longa methanol extract

\begin{tabular}{|c|c|c|c|}
\hline $\mathbf{S} / \mathbf{N}$ & Chemical compound name & Retention times (Mins) & Molecular formula \\
\hline 1 & 4-hydroxy-3-(2-oxo-2h-1-oxa-3-phenanthryl)-2(1h)-quinolone & 5.583 & $\mathrm{C}_{10} \mathrm{H}_{7} \mathrm{NO}_{4}$ \\
\hline 2 & 1,2,2-Trimethylcyclopropylamine & 7.717 & $\mathrm{C}_{6} \mathrm{H}_{13} \mathrm{~N}$ \\
\hline 3 & Glycine, N-[[(4-methoxyphenyl)methoxy]carbonyl]-N-methyl- & 8.717 & $\mathrm{C}_{25} \mathrm{H}_{23} \mathrm{NO}_{6}$ \\
\hline 4 & 1,E-11,Z-13-Octadecatriene & 15,517 & $\mathrm{C}_{18} \mathrm{H}_{32}$ \\
\hline 5 & 13-Heptadecyn-1-ol (CAS) 1-HYDROXY HEPTADEC-13-YNE & 15.942 & $\mathrm{C}_{17} \mathrm{H}_{32} \mathrm{O}$ \\
\hline 6 & Oleoylcholesterol & 16,267 & $\mathrm{C}_{45} \mathrm{H}_{78} \mathrm{O}_{2}$ \\
\hline 7 & 1H-Purin-6-amine, [(2-fluorophenyl)methyl]- & 16,775 & $\mathrm{C}_{12} \mathrm{H}_{10} \mathrm{FN}_{5}$ \\
\hline 8 & AR-TUMERONE & 18092 & $\mathrm{C}_{15} \mathrm{H}_{20} \mathrm{O}$ \\
\hline 9 & ALPHA.-TUMERONE & 18642 & $\mathrm{C}_{15} \mathrm{H}_{22} \mathrm{O}$ \\
\hline 10 & $6,9,12$-Octadecatrienoic acid, phenyl methyl ester & 23933 & $\mathrm{C}_{19} \mathrm{H}_{32} \mathrm{O}_{2}$ \\
\hline 11 & ARACHINSAEURE & 24383 & $\mathrm{C}_{20} \mathrm{H}_{40} \mathrm{O}_{2}$ \\
\hline
\end{tabular}

Table 2. Curcuma longa extracts and standards showing IC50 values

Samples analyzed $\quad$ IC50 values

\begin{tabular}{c|c} 
Curcuma longa methanol extract & $3.2 \mathrm{mg} / \mathrm{ml}$ \\
\hline Ascorbic acid standard & $5 \mathrm{mg} / \mathrm{ml}$
\end{tabular}

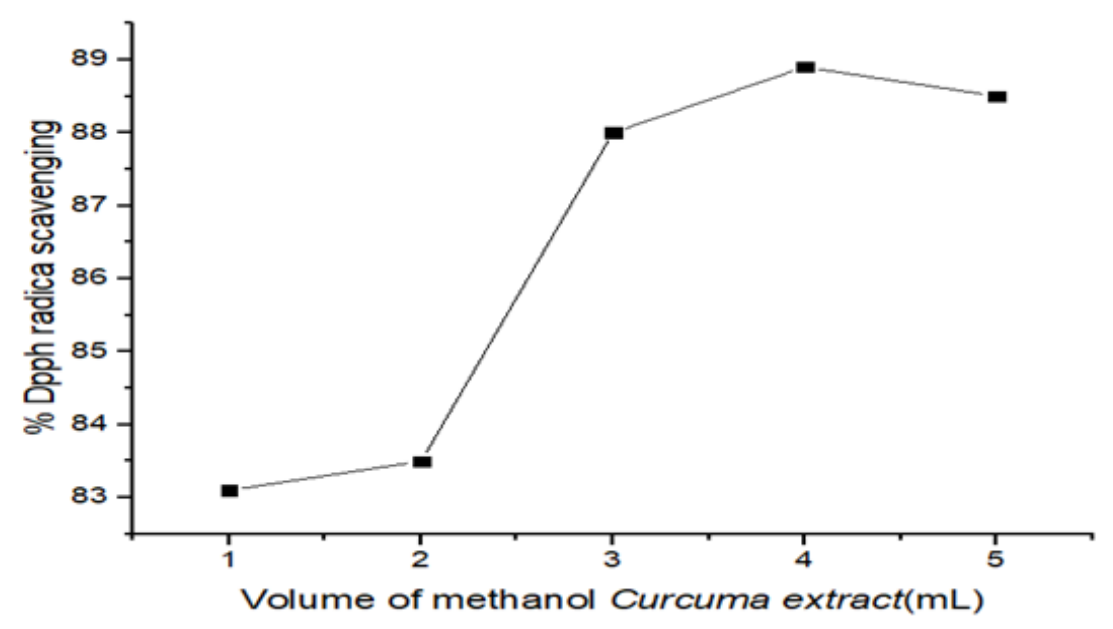

Figure 1. \% DPPH radical-scavenging according to the volume of $C$. longa

Table 3. Showing the minimum inhibitory concentrations (MIC) and minimum bactericidal concentration (MBC) for Staphylococcus aureus

\begin{tabular}{|c|c|c|c|c|}
\hline Microorganisms & \multicolumn{4}{|c|}{ Staphylococcus aureus (B-4420) } \\
\hline Concentration $(\mathbf{m g} / \mathbf{m l})$ & 50 & 25 & 12.5 & 6.25 \\
\hline Methanol turmeric extract & - & - & + & + \\
\hline
\end{tabular}




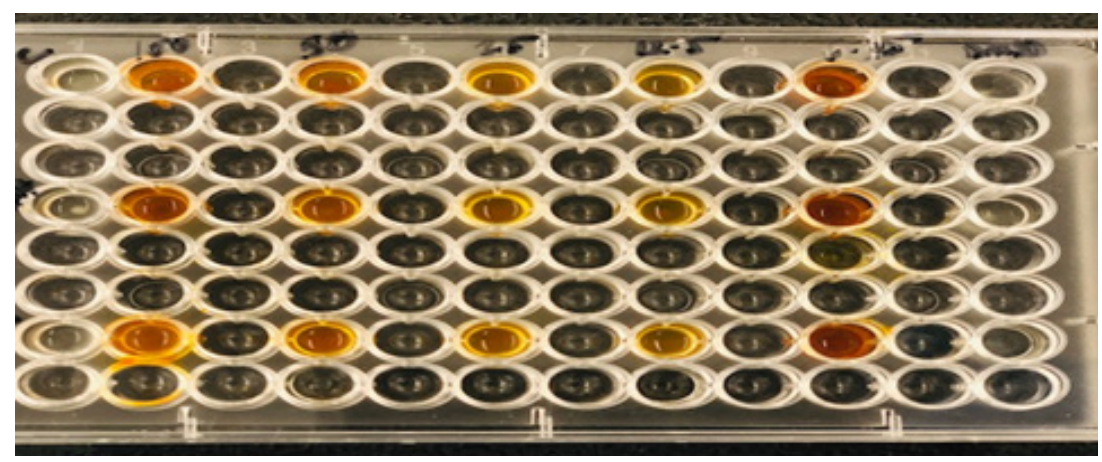

Figure 2. Mueller Hinton microplates showing MIC and MBC of Curcuma longa on Staphylococcus aureus

Table 4. Showing the zone of inhibition for Staphylococcus aureus by Duncan test

\begin{tabular}{|c|c|c|c|c|}
\hline \multirow{2}{*}{$\begin{array}{l}\text { Duncan }^{\mathrm{a}} \\
\text { CONS }\end{array}$} & \multirow{2}{*}{$\mathrm{N}$} & \multicolumn{3}{|c|}{ Subset for alpha $=.05$} \\
\hline & & 1 & 2 & 3 \\
\hline N (Dimethyl Sulfoxide) & 6 & 5,02 & & \\
\hline $\begin{array}{c}\text { Curcuma longa metha- } \\
\text { nol extract }\end{array}$ & 6 & & 8,07 & \\
\hline PEN (Penicillin G) & 6 & & 8,21 & \\
\hline $\begin{array}{l}\text { CHL (Chlorampheni- } \\
\text { col) }\end{array}$ & 6 & & & 12,83 \\
\hline Sig. & & 1,000 &, 791 & 1,000 \\
\hline
\end{tabular}

Means for each tested samples in homogeneous subsets are displayed.

a. Uses Harmonic Mean Sample Size $=6,000$.

changes in curcumin transport across and into the Caco-2 cells. Actually, in the presence of alpha, the measured curcumin amounts inside the cells and on the basolateral side of the monolayer were significantly increased which is one of the compounds responsible for antimicrobial activity according to (6). In addition, the solvent of extraction plays a role in adequate phenotyping and phytochemical examination in the GC-MS. Czernicka et al. (16) detected different substances in $C$. longa according to ours by LC-MS analysis as a result of methanol and diethyl ether extract. Kukula-Koch et al. (17) obtained many substances from $C$. longa with special solvent composed of heptane: chloroform: methanol: water mixture. Some of these items were similar to those in our study, while others differed. These researches show that lots of solvents can be used for extraction and different substance can be obtained if different analysis method and solvent are used. This situation might be as a result of the solvent of extraction which might interfere and alter the resultant constituents within the solvent (18).

This bottleneck is the rationale behind the focus of scientist on alternative orthodox or traditional means of sorting out human health problems by diet. Biomolecules have the ability.
Ascorbic acid was weighed and dissolved in both methanol. These methods were carried out to evaluate the antioxidant potential of $C$. longa methanol extracts and the interactions with free radicals. In vitro antioxidant assays have the potential to give a certain level of information that could contribute and give insight as to what happens in in vivo assay. Ascorbic acid has very high standard antioxidant activity, the percentage of DPPH scavenging activity appeared to increase as concentration increased for both the standard and the $C$. longa methanol extracts (Figure 1). The absorbance appeared to be unstable at some concentrations and it was in opposition with what Zhang et al. (9) reported in similar research. Compared to the IC50 values of Ascorbic acid which was $5 \mathrm{mg} / \mathrm{ml}, C$. longa methanol extract had a lower IC50 value is $3.2 \mathrm{mg} / \mathrm{ml}$ which according to previous literature is a good one given that lower IC50 values indicate great antioxidant activity (Table 2 ).

The zones of inhibition were measured after plating on a Mueller-Hinton agar plate and compared to the standards penicillin $\mathrm{G}$ and chloramphenicol. The methanol extract of $C$. longa has antimicrobial effect against $S$. aureus known as infectious disease agent as well as tested antibiotics (Table 4). The literature explains that a wider zone of inhibition describes the increased antimicrobial activity of certain agents over others. The research reported by Akter et al. (8) showed that $C$. longa methanol extract was effective on $S$. aureus and it could be as a result of a larger surface area on smaller sized turmeric components which makes it easier to access the interior cell wall compartment of these microbes. Differences in the susceptibility of $S$. aureus might be due to the variances in the cell wall structure, physiology and metabolism (4). Jalaluddin et al. (19) found that $C$. longa extract was effective on some periodontal pathogens; Porphyromonas gingivalis, Prevotella intermedia and Aggregatibacter actinomycetemcomitans. This indicates that there is at least one substance in C. longa that has antimicrobial effects on many bacterial species. In our study, the dominant inhibition of $C$. longa extract on a species that is resistant to Methicillin proves that the turmeric plant has a high antimicrobial effect. 


\section{Conclusion}

Curcumin has shown potent antioxidant, anticancer, antibacterial, antifungal activity and other pharmacological actions since 1950. Nowadays, Curcumin has been sold globally as a food and health supplement mainly for its anti-inflammatory and antioxidant properties. However, the GC-MS typing did not identify this curcumin, moreover research suggests that active agent for antimicrobial activity is curcumin. This indicates that different components other than curcumin, which are contained in $C$. longa, have an antimicrobial effect. C. longa methanol extract had a lower IC50 value with $3.2 \mathrm{mg} / \mathrm{ml}$ which according to previous literature is a good one given that lower IC50 values indicate great antioxidant activity. This result showed that $C$. longa methanol extract was effective on Methicillin-resistant $S$. aureus and it could be a potential antimicrobial agent with its contents against $S$. aureus

It has high potential to be developed into an antibiotic against Methicillin-resistant Staphylococcus aureus and other clinically important bacterial strains in future. However, in order to develop biologically more active curcumin and other substance derivatives available in C. longa, it is necessary to increase the number of studies and to test its effectiveness in situ and in vitro conditions by switching to the production of new generation synthetic products.

\section{References}

1. Angel GR, Menon N, Vimalaa B, Nambisan B. Essential oil composition of eight starchy Curcuma species. Ind Crops and Prod 2014; 60:233-238. doi: 10.1016/j.indcrop.2014.06.028.

2. Ilangovan M, Gunaab V, Hucde C, Naganandaa GS, Reddy N. Curcuma longa L. plant residue as a source for natural cellulose fibers with antimicrobial activity. Ind Crops and Prod 2018; 112: 556-560. doi: 10.1016/j.indcrop.2017.12.042.

3. Kutti Gounder D, Lingamallu J. Comparison of chemical composition and antioxidant potential of volatile oil from fresh, dried and cured turmeric (Curcuma longa) rhizomes. Ind Crops and Prod 2012; 38(1): 124-131. doi: 10.1016/j.indcrop.2012.01.014.

4. Rahman AFMM, Angawi RF, Kadi AA. Spatial localisation of curcumin and rapid screening of the chemical compositions of turmeric rhizomes (Curcuma longa Linn.) using Direct Analysis in Real Time-Mass Spectrometry (DARTMS). Food Chem 2015; 173: 489-494. doi: 10.1016/j.foodchem.2014.10.049.

5. Singh G, Kapoor IPS, Singh P, de Heluani CS, de Lampasona MP, Catalan CAN. Comparative study of chemical composition and antioxidant activity of fresh and dry rhizomes of turmeric (Curcuma longa Linn.). Food Chem Toxicol 2010; 48(4): 1026-1031. doi: 10.1016/j.fct.2010.01.015.

6. Tavares WS, Freitas SS. Grazziotti GH, Parente LML, Lião LM, Zanuncio JC. Ar-turmerone from Curcuma longa (Zingiberaceae) rhizomes and effects on Sitophilus zeamais (Coleoptera: Curculionidae) and Spodoptera fru- giperda (Lepidoptera: Noctuidae). Ind Crops and Prod 2013; 46: 158-164. doi: 10.1016/j.indcrop.2013.01.023.

7. Krishnakumar IM, Kumar D, Ninan E, Kuttan R, Maliakel BP. Enhanced absorption and pharmacokinetics of fresh turmeric (Curcuma Longa L) derived curcuminoids in comparison with the standard curcumin from dried rhizomes. J Funct Foods 2015; 17: 55-65. doi: 10.1016/j. jff.2015.04.026.

8. Akter J, Hossain MA, Takaraa K, Islam MZ, Hou D-X. Antioxidant activity of different species and varieties of turmeric (Curcuma spp): Isolation of active compounds. Comp Biochem Physiol C Toxicol Pharmacol 2019; 215: 9-17. doi: 10.1016/j.cbpc.2018.09.002.

9. Zhang L, Yang Z, Wei J, Su P, Chen D, Pan W, Zhou W, Zhang K, Zheng X, Lin L, Tang J, Du Z. Contrastive analysis of chemical composition of essential oil from twelve Curcuma species distributed in China. Ind Crops and Prod 2017; 108: 17-25. doi: 10.1016/j.indcrop.2017.06.005.

10. Vutakuri N. Curcumin - Breast Cancer Therapeutic Agent to Replace Allopathic Treatments with Extensive Side Effects. J Young Investig 2018; 35(2): 38-44. doi: 10.22186/ jyi.35.2.38-44.

11. Song X, Zhang M, Dai E, Luo Y. Molecular targets of curcumin in breast cancer (Review). Mol Med Rep 2019; 19(1): 23-29. doi: 10.3892/mmr.2018.9665.

12. Perrone D, Ardito F, Giannatempo G, Dioguardi M, Troiano G, Russo LL, de Lillo A, Laino L, Muzio LL. Biological and therapeutic activities, and anticancer properties of curcumin (Review). Exp Ther Med 2015; 10(5): 16151623. doi: 10.3892/etm.2015.2749.

13. Ukwubile CA, Ahmed A, Katsayal UA, Ya'u J, Mejida S. GC-MS analysis of bioactive compounds from Melastomastrum capitatum (Vahl)Fern. leaf methanol extract: An anticancer plant. Scientific African 2019; 3: 10-17. doi: 10.1016/j.sciaf.2019.e00059.

14. Hucklenbroich J, Klein R, Neumaier B, Graf R, Fink GR, Schroeter M, Rueger MA. Aromatic-turmerone induces neural stem cell proliferation in vitro and in vivo. Stem Cell Res Ther 2014; 5(4): 1-9. doi: 10.1186/scrt500.

15. Yue GGL, Cheng S-W, Yu H, Xu Z-S, Lee JKM, Hon P-M, Lee MYH, Kennelly EJ, Deng G, Yeung SK, Cassileth BR, Fung K-P, Leung P-C, Lau CBS. The role of turmerones on curcumin transportation and P-glycoprotein activities in intestinal caco-2 cells. J Med Food 2012; 15(3): 242-252. doi: 10.1089/jmf.2011.1845.

16. Czernicka L, Grzegorczyk A, Marzec Z, Antosiewicz B, Malm A, Kukula-Koch W. Antimicrobial potential of single metabolites of Curcuma longa assessed in the total extract by thin-layer chromatography-based bioautography and image analysis. Int J Mol Sci 2019; 20(4): 898. doi: 10.3390/ijms20040898

17. Kukula-Koch W, Grabarska A, Łuszczki J, Czernicka L, Nowosadzka E, Gumbarewicz E, Jarząb A, Audo G, Upadhyay S, Głowniak K, Stepulak A. Superior anticancer activity is demonstrated by the total extract of Curcuma 
longa L. as opposed to individual curcuminoids separated by centrifugal partition chromatography. Phytother Res 2018; 32(5): 933-942. doi: 10.1002/ptr.6035

18. Teow SY, Liew K, Ali SA, Khoo ASB, Peh SC. Antibacterial Action of Curcumin against Staphylococcus aureus: A Brief Review. J Trop Med 2016; 2016: 2853045. doi: $10.1155 / 2016 / 2853045$.

19. Jalaluddin M, Jayanti I, Gowdar IM, Roshan R, Varkey RR, Thirutheri A. Antimicrobial Activity of Curcuma longa L. Extract on Periodontal Pathogens. J Pharm Bioallied Sci 2019; 11(2): 203-207. 